\title{
Conversación con Cintia Pili: núcleos y logros de la lucha travesti-trans desde las organizaciones sociales
}

\author{
Maria Muro \\ Centro de Estudios Urbanos y Regionales - CONICET, \\ Argentina \\ maraia.muro@gmail.com \\ (iD) http://orcid.org/0000-0001-6322-5942 \\ Gimena Palermo \\ Universidad Nacional de La Plata - Centro de Estudios \\ Aplicados en Migraciones, Comunicación y Relaciones \\ Interculturales, Argentina \\ gimenapalermo@hotmail.com
}

(DD http://orcid.org/0000-0001-8657-5179

DOI: https://doi.org/10.24215/25457284e125

Recepción: 21 Mayo 2020

Aprobación: 08 Junio 2020

El pasado 9 de mayo se cumplieron ocho años de la sanción de la Ley de Identidad de Género en Argentina. Dicha ley, constituye un hito fundamental en la visibilización, reconocimiento e instauración de relaciones sociales inclusivas para un amplio sector de la población históricamente vulnerado: el colectivo travestitrans. ${ }^{1}$

Por supuesto que esta ampliación de derechos es producto de una larga historia de luchas y resistencias del conjunto del colectivo travesti-trans, en el que se han destacado por su labor y trayectoria muchxs referentes. En esta oportunidad tuvimos el gusto de conversar con una de sus representantes, Cintia Anahí Pili, el día 10 de mayo del año 2020, de la única manera que permite el aislamiento social preventivo y obligatorio: a través de plataformas virtuales.

Nacida en Balcarce (provincia de Buenos Aires) y residente de Mar del Plata, Cintia Pili ha sido noticia por ser la primera precandidata trans a un cargo político como consejera escolar de General Pueyrredón, en 2013 y 2015. Como asesora en el Consejo Deliberante, junto a otrxs compañerxs, formalizó la aplicación de la Ley Provincial de Cupo Laboral Travesti Trans No 14.783 “Diana Amancay Sacayán”, aprobada en el 2015, que establece un cupo para personas trans del $1 \%$ en dependencias públicas.

Forma parte de múltiples organizaciones: el Movimiento social, político y cultural "Atahualpa" de Mar del Plata que, junto a otras organizaciones, confluye en la Unión de Trabajadores de la Economía Popular (UTEP); conforma la Mesa de Diversidad de Género que está integrada por AMADI (Asociación Marplatense de Derechos por la Igualdad), AMI Mar del Plata (Asociación Mar del Plata Igualitaria), ATD (Asociación Todos por la Diversidad), GTM (Grupo Transparencia Mar del Plata), Nuevo Encuentro Diversidad de Género MDP, Red de personas viviendo con VIH, y Centro deportivo Social y Cultural Che Guevara.

Trabaja en la Dirección de Políticas de Género de la municipalidad de Mar del Plata, específicamente en el refugio Galé para mujeres en situación de violencia y sus hijxs. Asimismo, lucha por la promulgación de la ley "Reconocer es Reparar", que propone que el Estado reconozca a la comunidad travesti trans el daño ocasionado en sus vidas por la violencia institucional por su condición de género en democracia; a diferencia 
de la Ley Provincial 13.298 sancionada en Santa Fe (2018) que otorga el derecho a una pensión a personas trans detenidas durante la última dictadura. Tuvimos la oportunidad de conocer el proceso de la provincia santafecina a raíz de una entrevista que hicimos en septiembre de 2019 a Carolina Boetti y Marzia Echenique, primeras mujeres trans argentinas en percibir la reparación histórica por haber sido víctimas de la última dictadura como presas políticas por su condición de género. ${ }^{2}$

En la coyuntura actual de aislamiento social preventivo y obligatorio en el marco de la pandemia del COVID-19, se han profundizado las dificultades que la comunidad travesti-trans atraviesa como población vulnerable y en muchos casos de riesgo, razón por la que se ha constituido un Comité de emergencia LGTBIQ +. Esta situación fue relatada por Cintia en las páginas que siguen, además de compartir su trayectoria de vida, laboral y organizacional.

E- Comenzamos esta entrevista por un eje que tiene que ver con tu trayectoria de vida laboral y organizacional. Si bien conocemos algunas cuestiones clave de tu trayectoria, queremos preguntarte, ¿de qué manera te presentás frente a otrxs?

CP- Mi nombre es Cintia Pili, tengo 45 años y soy militante de derechos humanos, principalmente. Soy oriunda de la ciudad de Balcarce, vine de muy pequeña a la ciudad de Mar del Plata, lugar donde empieza mi recorrido militante. Me aboqué a la militancia del colectivo LGTBIQ+ por mi condición de compañera, de persona trans, travesti-trans. Mis inicios militantes se remontan muchos años atrás, cuando no podía transitar libremente por la calle porque había edictos que nos criminalizaban. Particularmente, había dos que les daban la posibilidad a las fuerzas policiales, con la complicidad del Poder Judicial, de llevarnos detenidas. Transité distintos caminos. Uno fue el de la prostitución, con el cual comienza mi activa militancia por el derecho a poder transitar libremente, y al que se sumaron otras compañeras de la ciudad de Mar del Plata. En ese momento no existían los avances que hay en la Argentina actualmente, que tienen que ver con el derecho a la identidad de género. Hoy, justamente, pasó un día del aniversario de los ocho años de la sanción de Ley de Identidad de Género. ${ }^{3}$ La identidad de género es la puerta que permite el acceso a otros derechos: al trabajo, a la salud, a la educación y todos los derechos básicos que debe tener cualquier ciudadana y ciudadano de la Argentina.

E- Cintia, hay momentos, situaciones, sucesos, que te han conducido a ser quien sos, como recién nos comentabas. ¿Podrías contarnos algunos hitos o instancias que consideres significativas en tu vida?

CP- Una de las cosas más importantes en mi vida tiene que ver con el derecho a la identidad. Hoy puedo gozar de tener un trabajo, soy trabajadora del hogar de tránsito Galé y de la Dirección de Políticas de Género. Ya hace seis años que soy empleada municipal. Tengo acceso a una obra social, a la salud integral, y también, por supuesto, aportes jubilatorios. Es muy significativo poder decir que tengo la posibilidad de tener una jubilación digna. Me siento privilegiada por esto, teniendo en cuenta que, en la Argentina, el 90\% de las compañeras travestis-trans se encuentra en situación de prostitución.

Por otro lado, el camino de la prostitución, que implicó estar detenida y no poder transitar libremente por la calle, me ha dejado secuelas, ciertos daños en mi vida. Sin embargo, de alguna manera, ese lugar tan oscuro y tan marginal me permitió también ser lo que soy hoy: una defensora de los derechos humanos. Muchas de nosotras creemos que poder habitar las calles sin que eso implique cometer un delito es una cuestión de derechos humanos, tal como el acceso a la identidad, y a todos los derechos como ciudadana. Y así lo manifestamos, cada vez que tenemos la posibilidad. En este caso, hablando con ustedes, o con un informe importante para la universidad. Espacio, este último, que también recorrí y dejé por distintos motivos, pero que tuve la posibilidad de habitarlo. Eso era algo que veíamos muy lejano, un beneficio y un espacio hermoso para nosotras, pero lo mirábamos de afuera. Por eso accedí a esta entrevista, porque me parece muy importante visibilizar una realidad que muchas veces se desconoce.

E- ¿Cómo fue tu acercamiento a la organización colectiva?

CP-Es muy interesante poder ser parte de un movimiento social como lo es el Movimiento Social y Político Atahualpa, con base aquí en Mar del Plata y que, desde hace unos años, integra el Frente de Pueblo Unido. Su 
importancia tiene que ver con la visibilidad, con la capacidad nuestra de, más allá de las cuestiones de género, trabajar territorialmente por problemáticas como la falta de alimento y la falta de trabajo.

En este espacio soy la referente de género y diversidad de la ciudad de Mar del Plata. También, formo parte de AMI (Asociación Mundo Igualitario). Hemos trabajado en el ámbito universitario, por ejemplo, con el cupo laboral trans, otro de los avances que queremos tener en legislación. Lamentablemente, la pandemia a nivel mundial y en la Argentina, no nos permitió poder acceder a esta ley. Buscamos que muchas compañeras puedan tener derecho al trabajo, algo que yo, como algunas tantas, pero muy pocas, hemos podido tener. Este es un derecho fundamental. Estas organizaciones nos han permitido visibilizar esta cuestión en el territorio.

Es clave para mí la participación dentro de los movimientos sociales porque son los primeros espacios sociales y políticos que nos han abierto las puertas. Más allá de los avances que hemos obtenido a nivel político, el derecho a la identidad es un derecho único que abarca todos los planos. Por ejemplo, la palabra "travesti" para mí es un concepto social, político y, por qué no, revolucionario.

E- ¿Cuáles fueron las motivaciones personales que te llevaron a integrar todas estas organizaciones sociales?

CP-Me motivó, en principio, la búsqueda de nuestra visibilidad, al igual que abrazar otras realidades de las cuales nos sentimos parte por haber sufrido la falta de derechos. Ese sufrimiento de las personas en los territorios, sobre todo de las niñeces, por no acceder al documento y a los derechos básicos como la alimentación, fue una motivación. Abrazar esas otras luchas y que ellos también abracen la nuestra, como una cuestión colectiva, fue uno de los motivos.

E- ¿Cómo podrías definir tu experiencia en la organización social? Si bien comentabas que tu rol específico es en cuestiones de género, ¿qué otras tareas desarrollás?

CP- Hago varias cosas. Me encargo de las cuestiones de género y de empoderar a las compañeras, sobre todo a las mujeres. Respecto a esto, un detalle muy importante de estas organizaciones sociales es que el 90\% son mujeres. Nuestras voces deben estar representadas en las organizaciones. Quienes hacen el trabajo más duro y más fuerte son las compañeras, en los barrios y en los territorios, con los merenderos y formando parte de distintas cooperativas.

También estoy a cargo del área social, con un equipo de compañeras. Si bien no soy trabajadora social, el hecho de ser parte del Estado me permite un mayor conocimiento de programas específicos que existen. En resumen, hago varias tareas, ya sea administrativas, acompañando las cuestiones de prensa, asisto a reuniones, y también en la parte política.

E- ¿Podés ahondar en algunas cuestiones que hayas impulsado desde la organización?

CP-Algunas de estas cuestiones que llevamos a cabo fueron capacitaciones en cuestiones de género y diversidad. Me parece que esto abre un abanico amplio, por ejemplo, en torno al empoderamiento de las compañeras, sobre todo en torno a la violencia. También he sido madrina de algunos merenderos. Me parece que mi participación dentro de la organización visibilizó una realidad que muchas personas desconocen. Esta cuestión, y el trabajo colectivo, son puntos específicos en los cuales aporto mucho a mi organización.

E- ¿Hay cosas que no se hayan hecho aún en las organizaciones sociales y que te gustarían hacer?

CP- La cuestión clave tiene que ver con el lugar que merecen ocupar nuestras compañeras: un lugar de conducción. Estos espacios han sido históricamente conducidos por varones. La conducción de la organización debe ser de las mujeres, me parece que eso es lo que falta. Más allá de esto, las organizaciones hacen un trabajo increíble. El impulso de muchas políticas públicas es gracias a que estas se movilizan, presentan proyectos en las cámaras legislativas y se reúnen con funcionarios. Aunque, podría decirse, que también es necesario que compañeras y compañeros formen parte de espacios políticos de toma de decisiones.

E-Siendo una referente del colectivo LGTB, ¿Podrías comentarnos acerca del proyecto de ley "Reconocer es reparar"?

CP- "Reconocer es reparar" es un proyecto de ley que presentamos en el año 2015. 'Lamentablemente, no tuvo tratamiento durante la gestión del gobierno anterior y, en este momento, se encuentra cajoneado. El objetivo es obtener, a través del proyecto, un resarcimiento a las personas mayores de 40 años que han 
sido detenidas en democracia en el marco de los edictos que nos criminalizaban. Eran dos los códigos contravencionales problemáticos, uno por "ejercer la prostitución" y el otro por "vestir ropa no apta al sexo". Imaginémonos, con estos nombres, lo antiguo de esas contravenciones. Tenemos muchísimas compañeras a las que les han quedado un montón de daños en su cuerpo. El proyecto busca concretar un resarcimiento a tanto daño causado por la policía, con la complicidad de las fuerzas de seguridad y el Poder Judicial, que instalaron una situación de represión en democracia. Cuando me refiero al Poder Judicial, justamente, hago una diferencia en lo que tiene que ver con la justicia. Este Poder fue cómplice de la policía en las detenciones y abusos que se llevaron a cabo. Este contexto impedía a las compañeras que nos encontrábamos detenidas en las comisarías acceder a un buen alimento o a visitas médicas. Hoy han sido derogados en todo el país, pero lo que se pide es el resarcimiento a quienes, cada vez que se las detenía, se les armaba un acta que quedaba guardada en un archivo. En ese archivo vamos a tener que trabajar en profundidad con el área de Acceso a la Justicia, para recuperar la documentación de esas contravenciones injustificables en etapa de democracia en la Argentina. A partir de este trabajo, proponemos que se dispense un monto que se corresponda con una pensión o una jubilación. Puedo asegurar que no son más de cien compañeras, porque las compañeras del colectivo travesti-trans no superan los 35-40 años de vida, más allá de los avances que hemos tenido.

Hago una aclaración respecto al dato de la esperanza de vida: estamos trabajando con los ministerios de Género y Diversidad de la Nación y de la Provincia para tener un informe oficial. Con el proyecto "Reconocer es reparar" buscamos que el Estado reconozca y repare tanto daño causado. ${ }^{5}$ A veces no se va a reparar, pero, al menos, estas compañeras van a tener una jubilación, entendiendo que no podrían acceder a la misma con cuarenta años, o que les va a costar terminar sus estudios y la dificultad de acceder al Cupo Laboral Trans. En realidad, son dos proyectos que están enmarcados en "Reconocer es reparar", uno comprende a quienes tengan menos de treinta y cinco años, y el otro de cuarenta años en adelante.

E- Respecto al proyecto de Ley, ¿lo piensan volver a presentar? ¿Cómo es la situación en este momento de pandemia?

CP- La pandemia retrasó todos los proyectos en general y este específicamente. Pero, desde este año, tenemos el Ministerio de Mujeres, Género y Diversidad, que no es un dato menor y es fruto de la lucha de todos los colectivos, de las mujeres feministas, y también del colectivo LGTBIQ+. Por ello, desde el Ministerio y desde esos espacios, vamos a impulsar estas políticas una vez que pase la cuarentena y podamos volver a trabajar en pos de ese objetivo.

E- ¿Qué otro tipo de actividades realizan en el marco de la organización?

CP- Nosotras, aquí en Mar del Plata, tenemos un polideportivo que se llama Che Guevara. Es el primer polideportivo barrial creado por una organización social. Realizamos muchas actividades culturales y deportivas como clases de zumba, de teatro y guitarra. Además, tenemos un espacio más cerca del centro que se llama Casa Pueblo Unido, donde se realizan talleres de canto y música, entre otras cosas. Por eso se llama Movimiento Social, Político y Cultural Atahualpa.

E- Nos interesaba indagar en tu trayectoria profesional y militante. Sabemos que, actualmente, trabajás en la Dirección de Políticas de Género. ¿Cuándo y cómo empezaste?

CP-Tengo una historia militante importante. En principio, fui la primera precandidata a consejera escolar a nivel mundial, es decir, en el ámbito educativo, en el año 2013 y en el año 2015.

En el año 2013, el intendente de aquel momento, me convocó a formar parte de su espacio político como candidata, como parte de la organización en la que milito. Si bien no se ganó la intendencia, yo tuve el placer de ingresar al municipio como la primera asesora trans del Concejo Deliberante de General Pueyrredón. Así comienza mi trayectoria en el Estado. Fue una experiencia maravillosa para mí, y creo que también para quienes formaban parte del Concejo Deliberante. Éramos veinticuatro concejalas acá en la ciudad de Mar del Plata. Luego, en el año 2015 fui nuevamente candidata. Esta vez no llegué a entrar en el concejo. Trabajé en un área del municipio que se llama "Presupuesto participativo". Esta es una herramienta que les permite a los barrios hacer obras colectivas, en pos de la inclusión de niñxs, ${ }^{6}$ de adultxs mayores. Más tarde, en el año 2015, 
pasé al área de Género y Diversidad, que en ese momento se denominaba Dirección de la Mujer. El cambio de nombre a Dirección de Género y Diversidad tiene que ver con la lucha que dimos para poder estar todxs incluidxs. Eso fue un logro. Comencé, además, a hacer horas extras en el hogar de tránsito Galé, donde van mujeres y niñxs víctimas de violencia interfamiliar. Me gustó esa tarea, soy cuidadora. Es un lugar donde se alojan mientras esperan las medidas preventivas como la restricción de acercamiento, para volver a su vida sin violencia. Pedí estar ahí, logré llegar por mi militancia, por presentar proyectos y golpear infinidad de puertas, con mucha capacidad y perseverancia. Sobre todo, presentando proyectos.

Mi primer acceso a un derecho fue a través de un Programa Social. Fue a lo primero que ingresé con mis compañeras.

Actualmente, participamos en Mar del Plata del programa Potenciar Trabajo, donde logramos que ingresen setenta personas. Desde el Comité de Emergencia LGBTIQ+ celebramos esta medida y estamos impulsando a las compañeras, para que en un primer acceso a una política pública puedan formarse y capacitarse. Esto es importantísimo. ${ }^{7}$

E- ¿Cómo están atravesando desde tu trabajo en la Dirección de Políticas de Género, por un lado, y desde la Organización de acción colectiva, por el otro, la situación específica de la pandemia?

CP-Es de público conocimiento que en la cuarentena los varones están más en sus casas y eso hace que se incremente la violencia exponencialmente. Esto se refleja en que el hogar Galé esté lleno. Tuvimos que habilitar un hotel acá en Mar del Plata porque llegamos a tener veinte personas alojadas, casi una situación de hacinamiento, siendo su capacidad para dieciséis. En consecuencia, también se incrementó el trabajo y el esfuerzo. A veces, llego a trabajar dieciséis horas por día. Nosotras no nos quedamos en nuestras casas, trabajamos más incluso ya que, por las circunstancias, algunas compañeras están con licencia extraordinaria por su edad o por algún problema de salud.

En cuanto a mi labor como militante, armamos un comité específicamente LGBTIQ+, dentro de los otros comités de crisis que se armaron por la pandemia. Se crearon en marzo, con el inicio de la cuarentena. Nos emocionó mucho la ciudadanía marplatense, cuando personas que nada tienen que ver con la diversidad hicieron donaciones de dinero a una cuenta bancaria. También conseguimos alimentos de parte del Estado. Sin embargo, no hemos tenido la necesidad de solicitar al Estado porque se sumaron muchos sindicatos, por ejemplo, el Sindicato de Trabajadoras Bancarias. Recibimos casi más de cien mil pesos en donaciones de dinero para comprar alimentos, que no es menor en este momento. Organizamos, en dos etapas, ciento veinte módulos alimentarios con productos alimentarios, de higiene personal y de limpieza. Estamos muy contentas con eso. La militancia es un concepto que no viene solo, tiene que ver con hacer algo que te gusta y te da placer. Este trabajo permite conocer las realidades de muchas compañeras que la están pasando muy mal, sobre todo porque el aislamiento no les permite ir a las calles, a la prostitución, que es el único sustento económico para poder vivir. Esperamos que pase pronto todo esto porque hay muchas situaciones muy complejas, compañeras indocumentadas y hacinamiento en las viviendas. Yo lo viví también, pero pensé que, a partir de la Ley de Identidad de Género, con un país con una mirada diferente, iba a ser distinto. De todas formas, estamos contentas con la cantidad de gente que se sumó a ayudar. También hay otros espacios trabajando por la contingencia. Acá hay muchos comités barriales, por ejemplo, integrados por distintas organizaciones que forman parte de la UTEP.

E- Además de las colectas y la organización barrial, ¿̇recibieron o reciben apoyo o propuestas desde dependencias estatales?

CP-En Mar del Plata hay un intendente de signo opositor al nacional y provincial. Si bien el gobierno local está articulando bastante con el gobierno nacional y provincial, lo que recibimos proviene, más que nada, de Nación y Provincia de Buenos Aires. A nivel local, se está haciendo muy poco en ese sentido.

Existe un nuevo programa que implementó el Ministerio de Desarrollo Social de la Nación: Potenciar Trabajo. Setenta personas del colectivo travesti-trans accedieron a este programa, que otorga un monto de dinero mensual para tareas o proyectos productivos, o estudios. 
E- ¿Qué proyectos, acciones, medidas te gustaría que se lleven a cabo?

CP- Obviamente medidas en relación con el acceso al trabajo. Creo que el trabajo dignifica. Yo siempre doy el ejemplo de mi experiencia, cuando tuve que estar parada en una esquina y salir todas las noches al frío y a tantas situaciones que se generan en la calle y en la prostitución. En el caso de los compañeros y compañeras de los barrios, el trabajo dignifica y permite un montón de otras cuestiones. Me parece que ahí hay que hacer foco. Espero que esta cuarentena y la pandemia no dejen devastado al país económicamente, y que se puedan generar alternativas, no solamente aquí en Mar del Plata.

En el ámbito local, las organizaciones sociales, políticas y culturales nunca dejaron de luchar y, más allá del contexto, siguen exigiendo al Estado municipal el acceso a las cooperativas. Hay cosas que se pueden hacer en este marco, por ejemplo, arreglar instituciones educativas. Las cooperativas tienen mucha capacidad para hacerlo.

En lo que respecta al gobierno provincial y nacional, creo que hay que felicitar a nuestro presidente por las medidas que ha tomado, logrando que no haya tanta cantidad de muertes y contagios en el país. Aunque sabemos que la pandemia va a complejizar las posibilidades económicas para poder continuar con los proyectos.

E- ¿Cuál fue el origen del comité de emergencia, para el colectivo LGTBIQ+? ¿Cómo se organizó?

CP-Surgió en los comités barriales, de los cuales formaba parte. En base a esta idea nos juntamos con distintas organizaciones como AMI (de la cual soy socia fundadora); 100\% Diversidad, que funciona a nivel nacional; Orgullo y Lucha, que también existe a nivel nacional; y el Movimiento Atahualpa. Entre todas decidimos conformar el comité, sin saber que había mucha gente que estaba dispuesta a sumarse y a donar. Más de ciento veinte compañeras accedieron a una ayuda alimentaria.

E- ¿Se reúnen con cierta periodicidad? ¿Tienen objetivos planteados como comité?

CP-Lamentablemente, no nos podemos reunir, pero sí nos juntamos cuando llegan las donaciones. Nos organizamos para ir a comprar los alimentos y armar las bolsas, con todas las medidas de prevención dispuestas por el gobierno. Tenemos varios objetivos. Trabajamos en pos del acceso a la identidad y a la salud de las compañeras que encontramos, que en muchos casos presenta una dificultad. El comité lo integran algunxs profesionales que trabajan ad honorem para acompañar. Puntualmente, trabajamos con dos abogadas, que son parte de AMI, para presentar un habeas corpus para compañeras que se encuentran privadas de la libertad en la unidad penal de Batán, por haber cometido delitos menores. Muchas viven con VIH o tienen problemas respiratorios y, en caso de que circule el virus dentro del pabellón, sería sumamente riesgoso. Una de ellas ya está en prisión domiciliaria, con las medidas correspondientes de monitoreo como la tobillera electrónica, porque estaba detenida por venta de estupefacientes, considerado un delito menor.

E- Es interesante resaltar lo que dijiste respecto a que muchas compañeras están sin trabajo por el aislamiento y porque no hay gente circulando en la calle. Nos gustaría saber tu posición sobre eso, pensando en la polémica entre el abolicionismo y el regulacionismo.

CP-Me parece una pregunta sumamente interesante porque, además es un debate que también se ha dado en los ámbitos académicos.

Yo siempre hablo de personas en situación de prostitución. Trabajé con personas en situación de prostitución que no lo eligieron. No implica que yo no acompañe la lucha de las mujeres por decidir sobre nuestros cuerpos. Por haber transitado ese camino debo decir claramente que la prostitución no es un trabajo, este concepto no está relacionado a la prostitución, desde ningún punto de vista. Al decir que no es un trabajo, no significa que esté en la vereda de enfrente y que condene a quienes se encuentran en esa situación, o consideran lo contrario. En mi opinión, relacionar la prostitución con el trabajo es abrir la posibilidad a las niñas para que se prostituyan, y este es un lugar de máxima violencia. Quizás las compañeras de distintas organizaciones, como AMMAR (Asociación de Mujeres Meretrices de la Argentina), deberían modificar el concepto de trabajo. Igualmente, cambiando ese concepto, la prostitución es una situación de máxima 
violencia, sobre todo para las mujeres. Avalando eso también estamos avalando que cualquier niña pueda elegirla como un trabajo.

E- ¿Y vos con AMMAR siempre tuviste este posicionamiento, esta diferencia? ¿Han tenido diálogo o algún trabajo vinculado?

CP-Sí, las conozco. He ido a congresos de AMMAR, y siempre tuve el mismo posicionamiento. El Cupo Laboral Trans, cuando Diana lo ideó, fue una idea abolicionista, con el fin de adquirir los derechos en igualdad de condiciones. Cuando me encontraba en posición de prostitución, me acuerdo que salió la Ley de Trata, creo que en el año 2010, que establece que en los diarios dejen de publicar lo que eran los clasificados del "rubro 59". A mí y a un montón de compañeras nos afectó muchísimo porque habíamos dejado de estar en la calle. Se implementó a raíz de la desaparición de Marita Verón y del impulso de su mamá. En aquel momento, muchas decían "pero nos mandan nuevamente a la calle", peleaban por eso. Es difícil hablar desde un lugar de comodidad, cuando esas compañeras lo único que tienen para el sustento económico es eso. Este es un debate que debe darse en profundidad. También, debo decir que hay mucho proxenetismo en algunos sectores. En conclusión, para mí, la prostitución no es ni será nunca un trabajo. Pensándola como tal, estamos avalando que una niña pueda decidir estar en una esquina.

E- Es muy interesante tu reflexión. Entendemos que no hay voz más autorizada para plantar posición, al haberlo vivido y experimentado.

CP - Por ahí se entrecruza la idea de "decidir en mi propio cuerpo". Nosotras no estamos decidiendo por el cuerpo de esas compañeras que dicen "yo amo la prostitución, me siento feliz con este trabajo porque esto me permite...". Cuando una tiene una posición distinta no por eso es una enemiga, ni tampoco hay una grieta ni estamos de la vereda de enfrente, sino que hay ciertos conceptos que no comparto.

E- ¿Te interesa Cintia participar activa y políticamente en este tema?

CP-He tenido debates y he ido a actividades, pero trato de ser respetuosa con ellas. Porque también son víctimas de un sistema. Claramente es eso, son víctimas de un sistema: el sistema capitalista y todas estas cuestiones. Cuando lo único que les da de comer es la prostitución es muy difícil plantear una posición diferente. Esperemos que salga el cupo y todas estas reivindicaciones por las que estamos luchando. Después de eso, nos sentamos a discutir.

Cintia Pili envuelta en la bandera de la disidencia sexogenérica junto a compañerxs. Fotógrafa: Romina Elvira

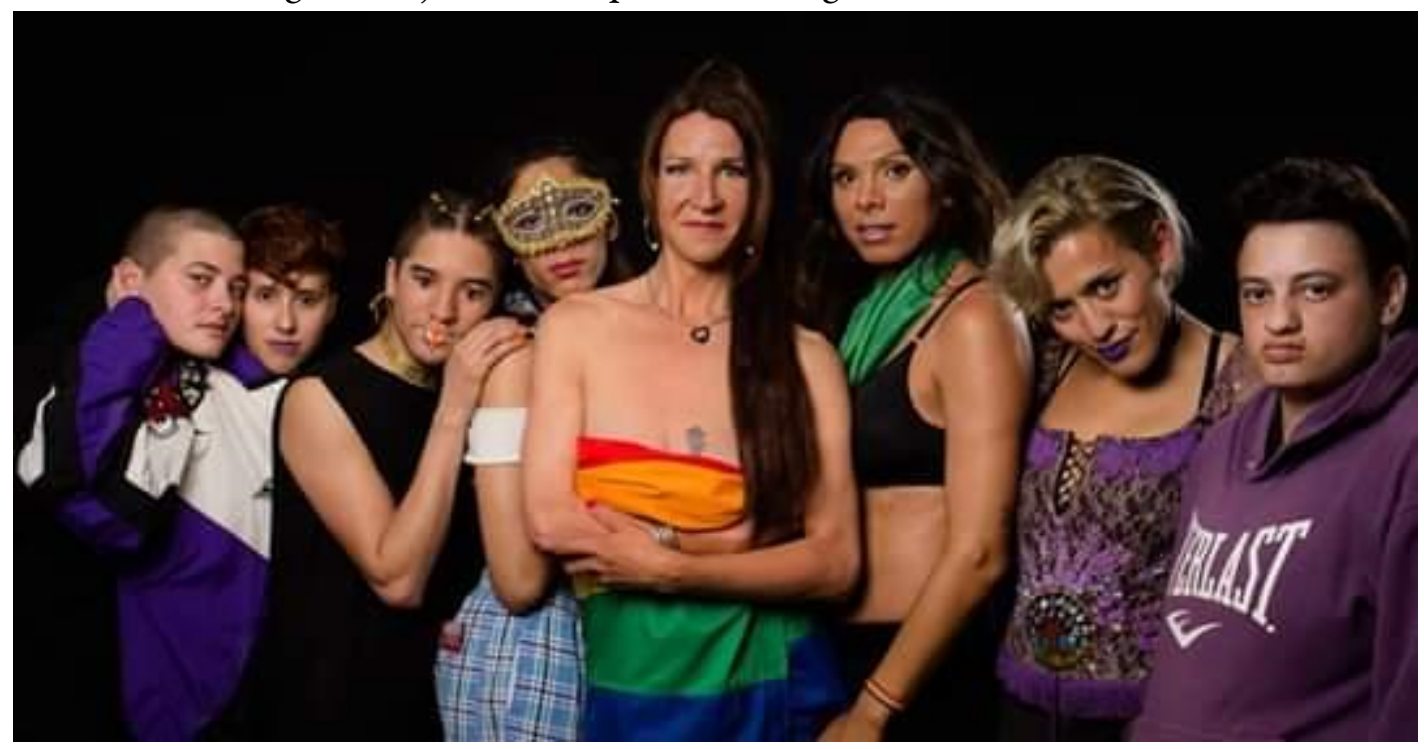

Fuente: Revista Ajo. Periodismo de largo aliento, 17 de noviembre de 2017. 
Apreciamos la atención y el tiempo que nos brindó Cintia Pili para realizar esta entrevista por videoconferencia, el 10 de mayo del 2020, en el actual contexto de emergencia sanitaria.

El relato de su historia es un recorrido por las luchas que se han llevado a cabo en las últimas décadas y que han permitido la conquista de derechos históricos como la Ley de Identidad de género.

Sus palabras ponen el acento en la profunda deuda de la democracia con el colectivo travesti-trans, y la búsqueda, que no pierde actualidad, por el derecho a transitar libremente por el espacio público. Asimismo, se expone en la conversación el trabajo que queda por delante en torno a los resarcimientos económicos, a la sanción de una Ley de Cupo Laboral Trans a nivel nacional, su implementación y cumplimiento en las provincias donde ya se haya sancionado y a la implementación de políticas públicas integrales que transformen esta realidad desigual. Retomando las palabras de Cintia, tener un Ministerio de Género y Diversidad no es poco, es una herramienta para la aplicación de esas políticas, y un vehículo para documentary relevar la situación en la que nos encontramos en materia de igualdad de derechos, porque el desconocimiento es invisibilización. Avanzar en el derecho al acceso a la salud, al trabajo y a la educación, son imperativos para seguir discutiendo cuestiones políticas que atraviesan a los feminismos y al colectivo travesti-trans. Entendemos que la academia y el ámbito universitario siguen siendo espacios donde luchar por la inclusión, por eso agradecemos profundamente a la entrevistada por su apertura, su confianza, y por permitir que un espacio, como lo es esta revista, se preste para visibilizar las conquistas pendientes.

Para contactarse con Cintia Pili: cintiapili2006@gmail.com

\section{Notas}

1 Ley de Identidad de Género No 26.743, sancionada el 9 de mayo de 2012. Reconoce la identidad autopercibida de las personas del colectivo trans y la posibilidad de ser inscritas en sus documentos personales con el nombre y el género vivenciado. Es la primera en el mundo que, conforme las tendencias en la materia, no patologiza las identidades trans. Fuente: http://servicios.infoleg.gob.ar/infolegInternet/anexos/195000-199999/197860/norma.htm

2 Disponible en Revista Debate Feminista. Debates Paralelos. Vol. 59 enero-junio 2020. CIEG - UNAM. ISSN: 0188-9478. Disponible en: https://debatefeminista.cieg.unam.mx/debates-paralelo.html

3 Video homenaje a las identidades travestis y trans integrantes de la Asesoría Civil Colectiva por un Mundo Igualitario (AMI), Mar del Plata. 9 de mayo de 2020. Disponible en: https://youtu.be/ahd6jfrlF0s

4 Proyecto de ley "Régimen Reparatorio para Víctimas de Violencia Institucional por motivos de identidad de género": $\mathrm{h}$ ttps://www.hcdn.gob.ar/proyectos/textoCompleto.jsp?exp=2526-D-2016\&tipo=LEY

5 Video publicado por TEA, el 19 de noviembre de 2016, en relación con proyecto: https://www.youtube.com/watch? $\mathrm{v}=\mathrm{cSXOvlihvSQ}$

6 Aclaramos, con respecto al uso del lenguaje inclusivo, que acordamos con nuestra entrevistada utilizar la " $x$ " en el formato escrito, aunque en la oralidad se ha expresado con la " $\mathrm{e}$ ", para que estén representadas todas las identidades, especialmente las no hegemónicas.

7 Sobre esta conquista del Comité de Emergencia LGBTIQ+, publicación Quédigital, 15-5-2020, disponible en: https:/ /quedigital.com.ar/politica/potenciar-trabajo-unas-70-personas-trans-de-mar-del-plata-accedieron-al-programa/

8 Se refiere a la ley $n^{\circ} n^{\circ} 26.842$ y su modificación $n^{\circ} 26.364$ de prevención y sanción de la trata de personas y asistencia a sus víctimas, sancionada el 19 de diciembre de 2012 y promulgada el 26 de diciembre de ese año.

\section{BY-NC-SA}

